precisa del mundo en que vivión. Y ello es evidentemente cierto. Pero al margen de las distorsiones a que ese punto de vista ha dado lugar en los últimos años (llevando a convertir a veces al artista en un mero "traductor visual» de las ideas de sus patronos, olvidando la especificidad del proceso de creación artística e incluso la propia individualidad del artista) cabe preguntarse si esa insistencia en los "alrededores» del proceso de creación no es un signo de la dificultad para avanzar más allá, por el momento, en la explicación del proceso evolutivo de Theotocopuli en España.

Conectado con este último punto está el bloque (relativamente abundante, pues comprende cinco trabajos) referido al "bizantinismo" del pintor y a la cuestión de la importancia de la "herencia bizantina» en su obra posterior (y especialmente la española). Seguramente no sin intención, el editor del volumen los ha incluido aparte, tras los estudios sobre los diferentes períodos y muy alejados de los dedicados al período cretense. Baste registrar aquí que, al margen de la insistencia en la cuestión de los préstamos iconográficos (caso de Hadermann-Misguich) y de la posible persistencia de métodos compositivos o estructurales (caso de S. Papadaki-Oekland), se plantean ahora vías nuevas, como hace D. Davies en su interesante estudio «The Byzantine Legacy in the Art of El Greco", en el que busca conectar el neoplatonismo de El Greco y las posibles conexiones de sus pinturas con los movimientos de reforma espiritual en España con las tradiciones de la pintura bizantina. La dificultad para contener este tipo de lecturas en sus justos límites, y de acotar debidamente las presuntas influencias, no tiene por qué ser resaltada aquí. Baste señalar, por lo que tiene de sintomático y por tratarse de un hecho casual, que una de las presuntas influencias bizantinas apuntadas en el volumen (la de las representaciones de S. Juan Evangelista con un discípulo en una cueva, que G. Galavaris presenta como fuente de las pinturas de El Greco con San Francisco y el hermano León meditando sobre la muerte) parece ser desmentida por D. Davies - sin pretenderlo éste- cuando, refiriéndose en su comunicación al contexto espiritual español, recuerda las cartas de Fr. Luis de Granada al arzobispo Carranza urgiéndole a retirarse al «yermo" y pone en conexión este tipo de actitudes con las representaciones de Theotocopuli de Santo Domingo y San Francisco.

El volumen se cierra con un amplio bloque de estudios referidos a la fortuna crítica de El Greco (recordemos la de E. Harris sobre "El Greco's 'Fortuna crítica' in Britain»), a la consideración de algunas de las lecturas que han conformado su imagen en nuestro tiempo (por ejemplo, la de Dvorák, estudiada por P. Klein, o la de Barrès, reconsiderada por N. Hadjinicolaou) y a su influencia o irradiación en el arte contemporáneo (con dos aportaciones especialmente relevantes: la de E. Foundoulaki sobre "Greco/Cézanne: la filière reperée par Picasso", y la de A. Boime sobre «The Americanization of El Greco»).

José Álvarez Lopera Universidad Complutense

\title{
UNA PRECISIÓN PARA LA BIOGRAFÍA DE TEODORO ARDEMANS
}

Una figura fundamental de nuestro Barroco que en los últimos tiempos ha sido objeto de amplios estudios es la de Teodoro Ardemans. En una publicación reciente, por la que se da a conocer la importante biblioteca que poseía el arquitecto ${ }^{1}$, se hace referencia a su primer matri-

1 Beatriz Blasco Esquivias: "Una biblioteca modélica. La formación libresca de Teodoro Ardemans (I)», Ars Longa, núm. 5, 1994, pp. 73-97. 
monio, con doña Isabel de Aragón, cuya celebración sitúa la autora «en una fecha temprana pero imprecisa en torno a $1685{ }^{\prime 2}$. En el curso de nuestras investigaciones en los diversos archivos de las parroquias madrileñas, tropezamos hace tiempo con el registro de este primer matrimonio, que se celebró concretamente el día 4 de agosto de 1681 en la iglesia parroquial de los Santos Justo y Pastor ${ }^{3}$, cuando Ardemans contaba tan sólo veinte años de edad. Literalmente, la partida de su matrimonio dice así:

(Al margen: Theodoro Ardemanes con Isabel de Aragón).

En la Villa de Madrid, a quatro días del mes de Agosto año de mil seiscientos y ochenta y uno, Yo, Joseph de Manzanares, Cura theniente desta Yglesia Parrochial de S. Justo y Pastor de dicha Villa, en virtud de Mandamiento de el Sr. Dr. D. Antonio Pascual, Vicario de ella y su Partido, despachado en dos deste dicho mes y año Por Juan Baptista Sáez Bravo, notario, Y no habiendo precedido ninguna de las tres amonestaciones que dispone y Manda el santo concilio de trento por haber dispensado dicho señor Vicario en todas ellas, Por justas causas que a ello le mobieron, y después de haberles tomado su mutuo consentimiento, desposé Por palabras de presente, que hacen Berdadero y Legítimo Matrimonio, a Theodoro Ardemanes con Isabel de Aragón, mis Parrochianos, estando en la calle de los embajadores, casas de Manuel del Olmo, siendo thestigos Christóbal Tello, Ysidro Rusexas y Andrés Pérez, y lo firmé. Joseph de Manzanares (firmado y rubricado).

Una anotación al margen se refiere a las «Vendiciones de primeras Nupcias», que recibieron igualmente en la parroquia de los Santos Justo y Pastor el 6 de febrero de 1682.

Parece más que probable que el propietario de las casas de la calle de Embajadores en las que habitaba Ardemans fuera el también conocido arquitecto Manuel del Olmo, y que el testigo Cristóbal Tello fuese el maestro de obras de igual nombre de que se hace mención en diversos documentos de la época ${ }^{4}$.

Natividad Galindo San Miguel Museo del Prado

\section{SANTA CATALINA DE SIENA Y LA GÉNESIS DEL RETRATO DE LA BEATA MADRILEÑA MARÍA ANA DE JESÚS (1564-1624)}

El 25 de mayo del año 1783, en un solemne acto celebrado en la Basílica Vaticana, es beatificada por Pio VI la religiosa mercedaria María Ana de Jesús ${ }^{\text {. }}$

La beata madrileña, había nacido en el año 1564 en el seno de una familia noble, su padre

2 Ob. cit., p. 75.

3 Madrid, archivo parroquial de San Justo y Pastor, fol. 449 del Libro De Despossorios y Belaciones de esta Iglessia Parrochial de Sant Iusto y Pastor de Madrid. Empieza desde IX. de Henero de M.DC.LXX.II.

${ }_{4}$ Virginia Tovar Martín: Arquitectos madrileños de la segunda mitad del siglo XVII, Madrid, Instituto de Estudios Madrileños, 1975, Manuel del Olmo, pp. 209-228; Cristóbal Tello, p. 221.

1 Bibliotheca Sanctorum, Roma (1967), vol. VIII, pp. 1032-1033. El decreto firmado por el Santo Padre, está fechado el 18 de Enero de 1783. En un breve del 13 de mayo del mismo año, se aprobaban los dos milagros atribuidos a la santa, produciéndose la solemne proclamación pública, doce días más tarde. 